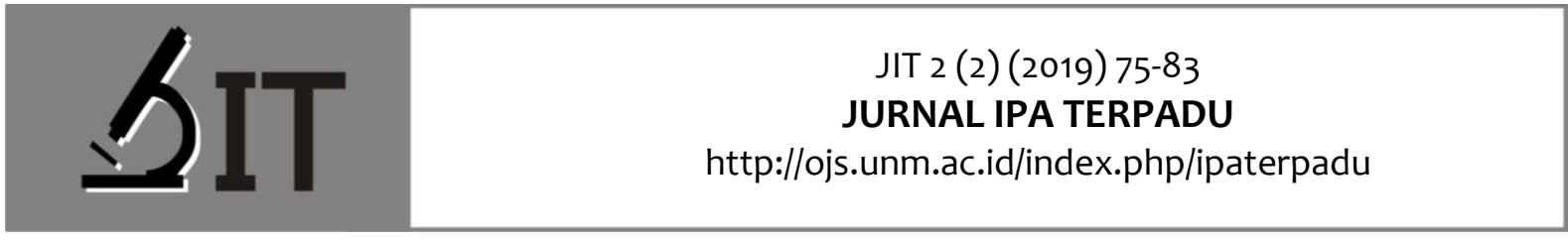

p-ISSN : 2597-8977

e-ISSN : 2597-8985
Saharuddin

SMP Negeri Limboro

Mawarni Wahab SMP Negeri Limboro

\section{ANALISIS KESULITAN DALAM PEMEBELAJARAN IPA DI SMP NEGERI LIMBORO}

Abstrak: Penelitian ini bertujuan untuk menemukan penyebab kesulitan yang dihadapi oleh guru mata pelajaran IPA terpadu di SMP Negeri Limboro. Penelitian menggunakan pendekatan Deskriptif Kuantitatif dan kualitatif dengan metode pengambilan data yakni analisis dokumen dan wawancara. Analisis dokumen dilakukan terkait dengan spesifikasi pendidikan guru IPA terpadu di SMP Negeri Limboro dan analisis hasil belajar peserta didik. Wawancara dilakukan kepada guru dengan menggunakan 8 pertanyaan yang terkait dengan masalah pembelajaran IPA. Hasil penelitian menujukkan kesulitan yang ditemukan dalam pembelajaran IPA di SMP Negeri Limboro secara umum disebabkan oleh dua hal yakni (1) dasar pendidikan guru IPA terpadu yang masih secara khsusu berasal dari pendidikan Biologi dan Pendidikan Fisika dan (2) Kekurangan sarana dan prasarana laboratorium yang menunjang praktikum mata pelajaran IPA. Secara umum solusi yang ditawarkan adalah pemberian pelatihan yang berkaitan dengan kontet IPA terpadu yang setara dengan 30 - 40 sks. Pelatihan seyogaynya diberikan oleh dinas pendidikan terkait disertai dengan identifikasi masalah serupa di kabupaten Polewali Mandar.

Kata Kunci : Guru IPA, Kesulitan Pembelajaran IPA

Abstract: This study aims to find the causes of difficulties faced by integrated science subject teachers in SMP Negeri Limboro. The study uses a quantitative and qualitative descriptive approach with data collection methods namely document analysis and interviews. Document analysis was carried out related to the specifications of integrated science teacher education in SMP Negeri Limboro and analysis of student learning outcomes. Interviews were conducted with the teacher using 8 questions related to the problem of learning science. The results of the study show that the difficulties found in science learning in SMP Negeri Limboro are generally caused by two things: (1) the basis of integrated science teacher education which is still specifically derived from Biology and Physics Education and (2) Lack of supporting laboratory facilities and infrastructure practicum for science subjects. In general, the solutions offered are the provision of training related to the integrated science counter that is equivalent to $30-40$ credits. Training should be provided by the relevant education office accompanied by identification of similar problems in Polewali Mandar district.

Keywords: Science Teacher, Science Learning Difficulties. 


\section{PENDAHULUAN}

Sesuai dengan amanat undang-undang sistem pendidikan nasional Indonesia No 20 tahun 2003 menyatakan bahwa pendidikan sebuah proses sadar dan dilakukan secara terencana dalam upaya melaksanakan proses belajar mengajar di dalam kelas agar perseta didik dapat menguasai keterampilan yang dimiliki dirinya. Salah satu keterampilan yang dibutuhkan adalah pengetahuan akan ilmu alamiah dasar bagi setiap peserta didik atau yang dikenal sebagai mata pelajaran IPA.

Pada pembelajaran saat ini, setelah kurikulum 2013 menggantikan kurikulum 2006, Pembelajaran IPA yang pelaksanaannya terpisah untuk fisika dan biologi, kini menjadi pembalajaran IPA terpadu. Implementasi dari pembelajaran IPA adalah guru harus mengajarkan IPA secara terpadu satu sama lain.

Hasil evaluasi yang dilakukan oleh Programme for International Student Assessment (PISA) pada tahun 2015 menunjukkan Indonesia berada di peringkat 62 sari 70 negara untuk kategari literasi sains. Meskipun posisi ini meningkat dari tahun 2012, namun hasil ini sangat jauh dengan beberapa negara di Asean seperti Singapura dan Vietnam yang berhasil masuk rangking 10 besar. Beberapa penyebab dari hal tersebut adalah fokus pembejalajaran IPA yang belum dipusatkan untuk menyelesaikan masalah literasi sains serta hanya pada pengetahuan faktual semata dan yang ke dua adalah peralihan guru pendidikan IPA di SMP yang sebelumnya mengajarkan bidang studi Fisika dan Biologi secara terpisah, kini diwajibkan untuk melakukan pembelajaran IPA IPA secara terpadu.

Pembelajaran IPA yang baik harus memiliki konten IPA terpadu yang benar diajarkan dua kompetensi yang baik, yakni penguasaan aspek pedagogic yang baik dan yang kedua adalah penguasaan konten. Cochran (1993) menyatakan bahwa pemahaman yang dimiliki oleh guru agar dapat mengajar dengan baik adalah pemahaman terkait dengan isi materi/konten, pengetahuan pedagogi, dan cara membelajarkan konten. Hal ini tentu saja menjadi penghambat pembejalaran IPA dimana sebelumnya system rekrutmen guru IPA berasal dari disiplin ilmu pendidikan Biologi dan pendidikan Fisika.

Selain penguasaan materi di dalam kelas, pembeljaran IPA yang baik harus dilaksanakan dengan proses praktikum untuk mencapai tujuan pemebljaran kompetensi IV yang berkaitan dengan Keterampilan. Subiantoro (2019) menyatakan bahwa esensi dari pembelajaran IPA adalah penguasaan akan metide ilmiah. Metode ilmiah ini dapat dilatih kepada peserta didik melalui kegiatan praktikum, sehingga praktikum dianggap sebagai hal yang tidak bias lepas dari pembeljaran IPA.

Pemberian proses praktikum tentu saja melibatkan pengetahuan yang holistik dari Guru di dalam laboratorium sehingga dapat memadukan pengetahuan dan keterampilan secara bersamaan. Senada dengan hal tersebut, Carin (1997) menjabarkan bahwa pembelaran IPA dapat terbentuk dari interrelasi berbagai aspek dari segi konten, sikap ilmiah, keterampilan proses baik dari Guru dan peserta didik yang mengikuti kegiatan dan proses pembelajaran IPA.

Pemebelajaran IPA yang dilaksanakan di SMP Negeri Limboro juga mengalami beberapa kendala. Lebih dari 70 \% peserta didik memiliki skor hasil belajar IPA di kelas IX tahun ajaran 20182019 yang tidak memenuhi KKM sekolah. Hal tersebut terutama terkait tiga kompetensi dasar yakni (1) Memahami berbagai sistem dalam kehidupan manusia, (2) Memahami kelangsungan hidup makhluk hidup dan (3) Memahami konsep kelistrikan dan penerapannya dalam kehidupan sehari-hari.

Tujuan dari penelitian ini adalah menganalisis kesulitan yang didapatkan oleh guru sekolah terkait dengan pembelajaran IPA di SMP Negeri 1 Limboro, serta memberikan rekomendasi baik bagi pihak sekolah dan guru dalam upaya menyelsaikan masalah tersebut.

\section{METODE}


Penelitian ini merupakan penelitian deskriptif dengan menggunakan metode analisis hasil belajar dan wawancara dengan guru pembelajaran IPA di SMP Negeri 1 Limboro. Penelitian ini melibatkan dua orang guru yang mengampuh mata pelajaran IPA di kelas IX.

Informasi dan data dikumpulkan dalam 2 kali pengambilan data dengan menggunakan metode wawancara untuk masing-masing Guru. Data yang diambil meliputi latar belakang pendidikan, proses pembelajaran yang diberikan dan hasil pemebaljaran IPA di kelas IX SMP Negeri 1 Limboro.

Analisis data yang digunakan adalah deskriptif kuantitaif dan kualitatif. Deskritpif kuantitatif digunakan pada analisis data hasil belajar dan deskriptif kualitatif digunakan pada analisis data wawancara dengan model open-ended question.

\section{HASIL DAN PEMBAHASAN}

Hasil observasi awal menunjukkan bahwa pelajaran IPA di SMP Negeri Limboro ditangani oleh dua orang guru dengan latar belakang pendidikan, akan tetapi tidak berasalah dari pendidikan IPA. Dua guru tersebut memiliki latar belakang Pendidikan Fisika dan Pendidikan Biologi.

Berdasarkan hasil wawancara struktur mata kuliah yang didapatkan selama menempuh proses pendidikan, keterampilan kekhususanan difokuskan ke materi masing-masing yakni fisika untuk pendidikan fisika dan biologi untuk pendidikan biologi. Sedangkan mata kuliah lintas disipilin dalam bidang ke-ipa-an hanya didapatkan paling banyak 3 SKS di semester awal pembelajaran. Sebagai contoh mata kuliah Fisika Dasar, Pengetahuan Lingkungan dan Kimia Dasar didapatkan oleh calon guru pendidikan Biologi sedangkan mata kuliah Biologi Umum, Pengetahuan Lingkungan dan Kimia Dasar didapatkan oleh calon Guru Fisika pada semester awal.

Tabel 1. Struktur Mata Kuliah Lintas Disiplin dalam Bidang Ke-Ipa-an

\begin{tabular}{ccc}
\hline Mata Kuliah & Pendidikan Fisika (jumlah SKS) & Pendidikan Biologi (Jumlah SKS) \\
\hline Fisika Dasar & $6 \mathrm{sks}$ & $3 \mathrm{sks}$ \\
Biologi Umum & $3 \mathrm{sks}$ & $6 \mathrm{sks}$ \\
Kimia Dasar & $6 \mathrm{sks}$ & $3 \mathrm{sks}$ \\
Pengetahuan Lingkungan & $2 \mathrm{sks}$ & $2 \mathrm{sks}$ \\
\hline
\end{tabular}

Data pada Tabel 1. Menunjukkan jika Guru Bidang studi Fisika mendapatkan lebih banyak jumlah mata kuliah untuk maya kuliah Lintas Disiplin dalam Bidang Ke-Ipa-an yakni sampai dengan 11 sks sedangkan untuk guru biologi hanya mendapatkan 8 sks. Hal ini disebabkan oleh perguruan tinggi yang menyusun mata kuliah sesuai dengan struktur kurikulum pada saat guru tersebut berstatus mahasiswa yakni kurikulum 2006 dimana pada saat itu Mahasiswa Pendidikan Biologi dan Pendidikan Fisika dipersiapkan untuk menjadi pengajar pada sekolah tingkat SMP dan SMA. Struktur kurikulum di SMP menujukkan bahan ajar Fisika memiliki kedalaman dan jumlah konten yang lebih banyak meskipun pada implementasi di kurikulum 2006 ke dua mata pelajaran ini prkatis terbagi sama.

Dari data ini dapat disimpulkan bahwa jumlah mata kuliah untuk materi ke-Ipa-an masih sangat kurang dimana struktur kurikulum LPTK memberikan $60 \%$ sampai dengan $80 \%$ atau setara dengan 80 sampai dengan 120 sks untuk konten materi. Jika asumsi ada mata kuliah saling beririsan sebanyak 50 \% mata kuliah, maka dapat disimpulkan jika Guru Pendidikan Fisika dan Guru Pendidikan Biologi kekurangan mata kuliah berisi Materi sebanyak 30 sampai dengan 40 sks.

Disisi lian untuk mata kuliah bidang pedagogik dianggap tidak memiliki masalah yang khusus saat digunakan untuk mengajar pada peserta didik tingkat Sekolah menengah pertama. Hal ini disebabkan karena strutur kurikulum LPTK pada masa guru tersebut kuliah memang disiapkan untuk mengajar pada tingkat SMP dan SMA. 
Tabel 2. Pertanyaan dan Jawaban yang Diberikan kepada dua responden atas pernyataan yang diajukan terkait dengan pembeljaaran IPA

\begin{tabular}{|c|c|c|}
\hline No & Pertanyaan & Jawaban \\
\hline 1 & $\begin{array}{l}\text { Selama mengajar mata Pelajaran IPA, } \\
\text { Menurut Bapak/lbu materi apa yang sulit } \\
\text { diajarkan? }\end{array}$ & $\begin{array}{l}\text { Responden I: } \\
\text { Materi yang sulit dibawakan itu materi yang } \\
\text { berkaitan dengan keanekaragaman hayati dan } \\
\text { clasifikasi mahluk hidup. Cakupan materinya } \\
\text { terlalu luas dan agak sulit untuk mengingat } \\
\text { semua matei terutama yang berkaitan dengan } \\
\text { Spesies dan Taksonomi-nya. Meskipun beberapa } \\
\text { materi sudah didapatkan waktu kuliah, tapi latar } \\
\text { belakang saya ada pendidikan fisika. } \\
\text { Responden 2: } \\
\text { Materi yang saya sulit ajarkan adalah materi } \\
\text { yang berkaitan dengan fisika, seperti Cahaya, } \\
\text { Optik, Listrik dan Magnet. Hitungnya terlalu } \\
\text { berat dan tidak pernah didapatkan di kampus } \\
\text { (Responden dua berasal dari pendidikan Biologi) }\end{array}$ \\
\hline & & $\begin{array}{l}\text { Materi yang membutuhkan praktikum juga sulit } \\
\text { dilaksanakan karena kekurangan fasilitas } \\
\text { laboratorium }\end{array}$ \\
\hline 2 & $\begin{array}{l}\text { Selama mengajarkan mata pelajaran IPA, } \\
\text { kendala apa saja yang bapak ibu } \\
\text { temukan? }\end{array}$ & $\begin{array}{l}\text { Responden I: } \\
\text { Kendalanya adalah mengingat nama-nama latin } \\
\text { yang berkaitan dengan spesies, genus, filum, } \\
\text { bagian dari taksonomi, system genetika dan } \\
\text { sistem reproduksi. }\end{array}$ \\
\hline & & $\begin{array}{l}\text { Responden 2: } \\
\text { Materi fisika yang banyak menenkankan konsep } \\
\text { dan juga yang membutuhkan praktikum, selain } \\
\text { konsep sedikit sulit dilakukan, hal-hal yang } \\
\text { berkaitan dengan praktikum juga sulit dilakukan. }\end{array}$ \\
\hline 3 & $\begin{array}{l}\text { Langkah apa sajakah yang bapak/ibu } \\
\text { lakukan dalam menangani masalah } \\
\text { tersebut? }\end{array}$ & $\begin{array}{l}\text { Responden I: } \\
\text { Biasanya sebelum mengajar, saya } \\
\text { memperbanyak membaca materi dan juga } \\
\text { melihat di internet. Sambil membuat RPP } \\
\text { dengan teliti serta seluurh perangkatnya, } \\
\text { terutama Power Pointnya } \\
\text { Responden 2: } \\
\text { Biasanya jika saya menemukan kesulitan, saya }\end{array}$ \\
\hline
\end{tabular}




\begin{tabular}{lll}
\hline No Pertanyaan & Jawaban \\
\hline \multirow{3}{*}{ Bagaimana cara Bapak/Ibu menyusun } & akan diskusi dengan rekan kerja yang lebih \\
& mengerti. Hanya saja jika waktunya tidak pas, \\
& terkadang agak kesulitan bertanya. \\
& Responden I: \\
& Caranya dengan mengkaji standar kompetensi \\
& yang telah diberikan oleh BSNP, lalu \\
& mendiskusikan dengan MGMP. Biasanya juga \\
& mencari sumber pembanding melalui internet \\
& Responden $2:$ \\
& Mengkaji dan mendiskusikan dengan teman \\
& pengajar lainnya, hal tersebut juga didisukusikan \\
& rapat tahunan.
\end{tabular}

5 Apakah ada kesulitan dalam menyusun perangkat pada mata pelajaran?

Responden I:

Sejauh ini sudah tidak ada, karena sudah banyak contohnya yang beredar di dunia maya, sisa di modifikasi sesuai dengan kebutuhan saja.

Responden 2 :

Kesulitannya jika dapat bagian materi yang tidak sesuai bidang, terkadang bingun menyusun materi IPA.

6 Apakah bapak ibu kesulitan Responden I:

mendapatkan bahan ajar?

Sejauh ini tidak ada masalah

Responden 2 :

Untuk materi tanpa praktikum sudah tidak masalah, hanya saja untuk materi yang membutuhkan praktikum.

7 Bagaimana hasil belajar IPA yang Responden I:

diperoleh siswa?

Sejauh ini sudah bagus dan memunuhi KKM kecuali pada beberapa materi seperti sistem reproduksi dan penyakit yang berhubungan dengan sistem reproduksi pada manusia.

Penjelasan agak sulit untuk disampikan ke Siswa SMP, karena kelas selalu riuh. Selain itu saya tidak begitu paham startegi menyampaikan materi tersebut, karena berkaitan dengan halhal yang dianggap tabu.

Responden 2 :

Sejauh ini materi yang disampaikan sudah lulus dengan KKM, kecuali beberapa materi khususnya yang ada hubungannya dengan 


\begin{tabular}{lll}
\hline No $\quad$ Pertanyaan & Jawaban \\
\hline \multirow{3}{*}{ Menurut hemat bapak ibu, bagaimana } & Fisika. & Responden I: \\
cara menyelesaikan masalah bapak/ibu & Seharusnya ada pelatihan khusus yang diberikan \\
dalam mengajarkan mata pelajaran IPA? & kepada guru yang tidak sebidang karena mata \\
& pelajaran IPA terpadu terbilang sulit diajarkan. \\
& Responden 2: \\
& Seharusnya ada pembagian mata pelajaran yang \\
& sesuai dengan mempertimbangkan klasifikasi \\
& pendidikan guru yang mengajar, jika memang \\
& harus mengajarkan IPA terpadu, paling tidak ada \\
& pemberian pelatihan atau beasiswa melanjtukan \\
& pendidikan S2 misalnya di pendidikan IPA. \\
\hline
\end{tabular}

Berdasarkan hasil wawancara tersebut dapat dilihat secara umum jika kesulitan yang ditemukan oleh guru mata pelajaran IPA adalah dispilin ilmu yang tidak bersesuaian, dimana guur IPa dengan latar belakang Biologi akan kesulitan mengajarkan materi IPA yang berkaitan dengan Fisika, dan begitu pula sebaliknya.

Hal ini disebabkan oleh perubahan kebijakan pembelajaran IPA di sekolah menengah oleh karena itu guru-guru IPA pada masa peralihan akan menemukan kesulitan berkaitan dengan kebijakan tersebut. Sistem rekrutmen guru IPA yang memiliki latar belakang Pendidikan IPA masih sangat kurang sedangkan guru-guru IPA yang telah direkrut menggunakan kurikulum terdahulu masih terpisah antara IPA dan kekhususan Fisika, Biologi, Kimia dan Lingkungan.

Kekurangan ini dapat tercermin dari kekurangan konten keterkaitan antara keipaan seperti yang telah ditunjukkan tabel 1 dimana guru-guru IPA dengan latar belakang Pendidikan Fisika dan Bilogi paling kekurangan 30 sampai dengan 40 SKS yang berkiatan dengan Ke-IPA-an. Kekurangan ini berdampak pada kesulitan guru-guru menyajikan pembelajaran IPA terpadu sesuai dengan amanat undang-udang pendidikan mengenai mata pelajaran IPA.

Secara normative, seharusnya guru-guru dikembalikan sesaui dengan pendidikan mereka, dimana Fisika dan Biologi hanya akan ditemukan pada tingkat sekolah Menengah atas, namun masalah tersebut adanya perubahan system pengeloalah tenaga pengajar atau Guru pada tingkat SMP dan SMA membuat perpindahan Guru dari SMP dan SMA akan sulit terelisasikan. Kebijakan pengelolahan Guru SMP dikelola oleh dinas pendidikan pada tingkat kabupaten dan guru SMA dikelola oleh dinas pendidikan pada tingkat provinsi. Perlu dipertimbangkan juga rasio guru IPA dengan bidang keahlian pendidikan IPA dengan jumlah yang masih sangat terbatas, sehingga kebijakan menempatkan guru sesuai dengan bidang keahlianya akan sulit untuk dilakasanakan dalam waktu dekat.

Solusi yang paling mudah adalah memberikan pelatiahn tamabhan kepada guru-guru IPA yang telah mengajar untuk diberikan pengetahuan dan keterampailan tambahan yang berbeda dengan dengan bidang keahlian namun dalam lingkup ke-IPA-an. Pelatihan yang diberikan sebaiknya dalam bentuk pelatihan yang setara dengan 40 SKS mata kliah agar guru-guru IPA dapat menguasai dan mengajarkan mata pelajaran IPA terpadu dengan benar.

Tabel 3. Standar Kompetensi dan Kompetesi Dasar yang Tidak Tuntas pada Mata Pelajaran IPA SMP Negeri Limboro tahun Ajaran 2018/2019 


\begin{tabular}{|c|c|c|c|c|}
\hline No & $\begin{array}{c}\text { Standar } \\
\text { Kompetensi }\end{array}$ & Kompetensi Dasar & Indikator & $\begin{array}{c}\text { Pesan dan Analisis } \\
\text { Perbaikan }\end{array}$ \\
\hline \multirow[t]{2}{*}{1} & $\begin{array}{l}\text { Memahami } \\
\text { berbagai sistem } \\
\text { dalam kehidupan } \\
\text { manusia }\end{array}$ & $\begin{array}{l}\text { 1.2. Mendeskripsikan } \\
\text { sistem } \\
\text { reproduksi dan } \\
\text { penyakit yang } \\
\text { berhubungan } \\
\text { dengan sistem } \\
\text { reproduksi pada } \\
\text { manusia }\end{array}$ & $\begin{array}{l}\text { - Mendeskripsikan fungsi } \\
\text { sistem reproduksi } \\
\text { - Menulis artikel tentang } \\
\text { cara penularan dan } \\
\text { pencegahan penyakit } \\
\text { yang berhubungan } \\
\text { dengan sistem } \\
\text { reproduksi }\end{array}$ & $\begin{array}{l}\text { Diperlukan media } \\
\text { pembelajaran dan } \\
\text { metode } \\
\text { pembelajaran yang } \\
\text { lain yang lebih } \\
\text { menarik dan } \\
\text { diperbanyak } \\
\text { gambar agar } \\
\text { peserta didik dapat } \\
\text { mencapai indikator } \\
\text { tersebut }\end{array}$ \\
\hline & & $\begin{array}{l}\text { 1.3. Mendeskripsikan } \\
\text { sistem koordinasi } \\
\text { dan alat indera } \\
\text { pada manusia } \\
\text { dan hubungannya } \\
\text { dengan } \\
\text { kesehatan }\end{array}$ & $\begin{array}{l}\text { Mendeskripsikan } \\
\text { bagian-bagian sistem } \\
\text { saraf dan fungsinya }\end{array}$ & $\begin{array}{l}\text { Peserta didik } \\
\text { kurang memahami } \\
\text { bagian-bagian } \\
\text { sistem saraf jadi } \\
\text { media } \\
\text { pembelajaran } \\
\text { ditambah lagi dan } \\
\text { dibuat semenarik } \\
\text { mungkin serta } \\
\text { penugasan } \\
\text { ditambah }\end{array}$ \\
\hline 2 & $\begin{array}{l}\text { Memahami } \\
\text { kelangsungan } \\
\text { hidup makhluk } \\
\text { hidup }\end{array}$ & $\begin{array}{l}\text { 2.3. Mendeskripsikan } \\
\text { proses pewarisan } \\
\text { dan hasil } \\
\text { pewarisan sifat } \\
\text { beserta } \\
\text { penerapannya }\end{array}$ & $\begin{array}{l}\text { - Menentukan gamet } \\
\text { dari genotip } \\
\text { tetua/induk } \\
\text { - menentukan rasio hasil } \\
\text { persilangan } \\
\text { persilangan } \\
\text { monohibrida dan } \\
\text { dihibrida melalui bagan }\end{array}$ & $\begin{array}{l}\text { Perbanyak latihan } \\
\text { atau penugasan } \\
\text { kepada peserta } \\
\text { didik terutama } \\
\text { dalam menghitung } \\
\text { dua sifat beda atau } \\
\text { dihibrid }\end{array}$ \\
\hline \multirow[t]{2}{*}{3} & $\begin{array}{l}\text { Memahami } \\
\text { konsep } \\
\text { kelistrikan dan } \\
\text { penerapannya } \\
\text { dalam kehidupan } \\
\text { sehari-hari }\end{array}$ & $\begin{array}{l}\text { 3.1. Mendeskripsikan } \\
\text { muatan listrik } \\
\text { untuk memahami } \\
\text { gejala-gejala } \\
\text { listrik statis serta } \\
\text { kaitannya dalam } \\
\text { kehidupan sehari- } \\
\text { hari }\end{array}$ & $\begin{array}{l}\text { - Menjelaskan secara } \\
\text { kualitatif hubungan } \\
\text { antara besar gaya } \\
\text { listrik dan besar } \\
\text { muatan listrik serta } \\
\text { jarak antara benda } \\
\text { bermuatan listrik }\end{array}$ & $\begin{array}{l}\text { Diperbanyak lagi } \\
\text { contoh soal agar } \\
\text { peserta didik dapat } \\
\text { menghitung } \\
\text { komponen- } \\
\text { komponen yang } \\
\text { berkaitan dengan } \\
\text { gaya Colomb }\end{array}$ \\
\hline & & $\begin{array}{l}\text { 3.2. Menganalisis } \\
\text { percobaan listrik } \\
\text { dinamis dalam }\end{array}$ & $\begin{array}{l}\text { - Membuat rangkaian } \\
\text { komponen listrik } \\
\text { dengan berbagai }\end{array}$ & $\begin{array}{l}\text { Selain praktikum } \\
\text { sebaiknya pada } \\
\text { materi ini media }\end{array}$ \\
\hline
\end{tabular}




\begin{tabular}{|c|c|c|c|c|}
\hline No & $\begin{array}{c}\text { Standar } \\
\text { Kompetensi }\end{array}$ & Kompetensi Dasar & Indikator & $\begin{array}{c}\text { Pesan dan Analisis } \\
\text { Perbaikan }\end{array}$ \\
\hline & & $\begin{array}{l}\text { suatu rangkaian } \\
\text { serta } \\
\text { penerapannya } \\
\text { dalam kehidupan } \\
\text { sehari-hari }\end{array}$ & $\begin{array}{l}\text { variasi baik seri } \\
\text { maupun paralel } \\
\text { - Mengukur dan } \\
\text { menggambarkan arus } \\
\text { listrik dan beda } \\
\text { potensial dalam } \\
\text { bentuk tabel dan } \\
\text { grafik. } \\
\text { - Menyelidiki hubungan } \\
\text { antara arus listrik dan } \\
\text { beda potensial dalam } \\
\text { suatu rangkaian } \\
\text { (Hukum Ohm) }\end{array}$ & \begin{tabular}{lr}
\multicolumn{2}{l}{ pembelajaran } \\
disajikan & terlebih \\
dalam & bentuk \\
video & untuk \\
mengukur & \\
rangkaian & tersebut \\
sehingga sebelum & praktikum \\
didik & sudah \\
mengetahui & cara \\
menyusun & \\
rangkaian & agar \\
waktu & yang \\
digunakan & saat \\
praktikum & tidak \\
terlalu lama &
\end{tabular} \\
\hline
\end{tabular}

Data pada tabel 3 menunjukkan standar Kompetensi dan Kompetensi dasar yang tidak mencapai KKM. Ketiga materi tersebut terdistribusi pada guru mata pelajaran yang tidak sesaui bidang pendidikan dasar yakni SK 1 dan SK 2 yang diajarkan oleh guru IPA berlatar belakang pendidikan Fisika dan sedangkan untuk SK 3 diajarkan oleh guru IPA berlatar belakang Pendidikan Biologi.

Kendati pada masa menempuh pendidikan, Guru - Guru IPA di SMP Negeri Limboro mendapatkan mata kuliah yang saling berkaitan namun kesulitan yang dialami oleh guru adalah mengajarkan materi yang spesifik.

Selain dari segi kompetensi yang dimiliki oleh guru IPA, beberapa materi IPA juga sulit diajarkan kepada peserta didik karena keterbatasan sarana dan prasarana sekolah, terutama halhal yang berkaitan dengan praktikum. Senada dengan hal tersebut, Said (2014) menyatakan kegiatan praktikum dianggap bagian yang sangat penting dalam menyampaikan konsep kepada peserta didik.

\section{KESIMPULAN}

Kesulitan yang ditemukan dalam pembelajaran IPA di SMP Negeri Limboro secara umum disebabkan oleh dua hal yakni (1) dasar pendidikan guru IPA terpadu yang masih secara khsusu berasal dari pendidikan Biologi dan Pendidikan Fisika dan (2) Kekurangan sarana dan prasarana laboratorium yang menunjang praktikum mata pelajaran IPA. Secara umum solusi yang ditawarkan adalah pemberian pelatihan yang berkaitan dengan kontet IPA terpadu yang setara dengan 30 - 40 sks. Pelatihan seyogaynya diberikan oleh dinas pendidikan terkait disertai dengan identifikasi masalah serupa di kabupaten Polewali Mandar.

\section{DAFTAR PUSTAKA}

Carin, Arthur A. 1997. Teaching Science Through Discovery, 8th edition. Ohio: Merrill Publ. Co. 
Cochran, K.F.,DeRuiter, J.A., dan King, R.A. 1993. Pedagogical Content Knowing: An Integrative Model for Teacher Preparation. Journal of Teacher Education, 44 (4): 263-272.

Diamond, I. 2011. Science Education in Schools. London: TLRP Institute of Education University of London.

Said, Ziad (2014) The Importance of Practical Activities In School Science: Perspectives Of Independent School Teachers In Qatari Schools. EDULEARN14 Conference. Barcelona Spain. Volume: pp. 4847-4856

Subiantoro, A.W (9 Juni 2019). Pentingnya Praktikum dalam Pembelajaran IPA. Diakses dari laman http://staffnew.uny.ac.id/upload/132309690/pengabdian/PPM_PENTINGNYA+PRAKTIKUM .pd

Received 25 June 2018

Accepted, 20 Febaruari 2019

\section{Saparuddin}

Kepala SMP Negeri 1 Limboro

Mawarni Wahab

Guru IPA SMP Negeri 1 Limboro 